University of Warwick institutional repository: http://go.warwick.ac.uk/wrap This paper is made available online in accordance with publisher policies. Please scroll down to view the document itself. Please refer to the repository record for this item and our policy information available from the repository home page for further information.

To see the final version of this paper please visit the publisher's website. Access to the published version may require a subscription.

Author(s): Silvia Schneider, Jiske E. G. Houweling , Susan GommlichSchneider · Cordelia Klein · Birgit Nündel, Dieter Wolke Article Title: Effect of maternal panic disorder on mother-child interaction and relation to child anxiety and child self-efficacy Year of publication: Forthcoming Link to published:version: http://www.springer.com/springerwiennewyork/medi cine/journal/737

Publisher statement: The original publication is available at www.springerlink.com 


\title{
Effect of maternal panic disorder on mother-child interaction and relation to child anxiety and child self-efficacy
}

\author{
Silvia Schneider ${ }^{*} \cdot$ Jiske E. G. Houweling \\ Department of Clinical Child and Adolescent Psychology, \\ University of Basel, Missionsstrasse 60/62, Switzerland \\ Susan Gommlich-Schneider · Cordelia Klein · Birgit Nündel \\ Technische Universität Dresden. \\ Mommsenstrasse 9, 01062 Dresden, Germany \\ Dieter Wolke \\ Department of Psychology, University of Warwick, \\ Coventry, CV4 7AL, Great Britain
}

\footnotetext{
* Corresponding author at: Department of Clinical Child and Adolescent Psychology, University of Basel, Missionsstrasse 60/62, 4005 Basel, Switzerland.

Tel.: +41-61-2670340; Fax.: +41-61-2670339

E-mail address: silvia.schneider@unibas.ch
} 


\begin{abstract}
To determine whether mothers with panic disorder with or without agoraphobia interacted differently with their children than normal control mothers, 86 mothers and their adolescents (aged between 13 and 23 years) were observed during a structured play situation. Maternal as well as adolescent anxiety status was assessed according to a structured diagnostic interview. Results showed that mothers with panic disorder/agoraphobia showed more verbal control, were more criticizing and less sensitive during mother-child interaction than mothers without current mental disorders. Moreover, more conflicts were observed between mother and child dyadic interactions when the mother suffered from panic disorder. The comparison of parenting behaviors among anxious and nonanxious children did not reveal any significant differences. These findings support an association between parental over-control and rejection and maternal but not child anxiety and suggest that particularly mother anxiety status is an important determinant of parenting behavior. Finally, an association was found between children's perceived self-efficacy, parental control and child anxiety symptoms.
\end{abstract}

Keywords: Maternal panic disorder, Mother-child interaction, Parenting, Child anxiety, Perceived self-efficacy 
Although there has been extensive research into developing a more refined understanding of the nature and maintenance of panic disorder/agoraphobia, little attention has been given to the understanding of its origins. Since there is a high familial transmission of panic disorder (e.g. Weissman 1993), one area worthy of exploration is the potential influence of parenting factors in the development of panic disorder/agoraphobia. This aspect in the etiology of panic disorder/agoraphobia was emphasized very early on by Goldstein and Chambless (1978). More recently, Bouton et al. (2001) stated, in their learning theory on the etiology of panic disorder, that early experiences with excessive control and overprotection (e.g. parents who do not respond to their children's needs, requests, and initiatives in a consistent manner) may produce a sense of lack of control and mastery over children's environments and that this may serve as a psychological vulnerability factor for panic disorder and anxiety disorders in general. However, there is a paucity of empirical research examining this possibility. So far studies investigating this question in panic disorder used retrospective data gathered by questionnaires and mainly focused on the two principal parenting dimensions suggested by Bowlby (1977), namely "care" (i.e. caring versus indifference/rejection) and "over-protection" (i.e. control/overprotection versus autonomy granting and independence). These studies consistently showed that patients with panic disorder/agoraphobia described their parents as less caring than did normal controls (e.g. Arrindell et al. 1983; Arrindell et al. 1989; Parker 1979). However, results for 'over-protection' are inconsistent, with some studies reporting more over-protection by both parents (Faravelli et al. 1991; Wiborg and Dahl 1997) or by the mother (Parker et al. 1997; Silove et al. 1991) for the offspring of parents with panic disorder during comparisons with the offspring of diagnosis free parents, whereas other studies could not find an association (Arrindell et al. 1983; Arrindell et al. 1989; Parker 1979).

Early observational studies have analysed the ongoing interaction between the parent with an anxiety disorder and their child (with or without assessment of child diagnosis). However, these studies used groups of patients with mixed anxiety disorders instead of "pure" groups of parents with panic disorder. A study by Hirshfeld et al. (1997) analysed the role of maternal anxiety in influencing “expressed emotion” (EE) and observed that mothers with anxiety disorders were more critical of their children than psychiatric control mothers. Whaley and colleagues (1999) explored parent-child interactions during neutral and conflict-promoting tasks and found anxious mothers to be less warm, grant less autonomy and be more critical than normal control mothers. Subsequently, Moore et al. (2004) searched to determine which parenting behaviors are more closely related to parent diagnosis, child diagnosis, or a combination of both. They found that mothers of anxious children expressed less warmth and granted less autonomy to their children, regardless of their own anxiety status. Conversely, Turner et al. (2003) and Woodruff-Borden et al. (2002) detected no evidence for more 
control between parents with and without an anxiety disorder when children were engaged in fear-related tasks.

A recent longitudinal study (Ginsburg et al. 2004), assessing parent-child interaction using an Etch-ASketch task (i.e. requiring parent and child to work together in order to succeed), found that among anxious parents, lower level of granting of autonomy and higher levels of criticism in $1^{\text {st }}$ grade were significantly related to higher anxiety symptoms 6 years later. Interestingly, cross-sectional analyses did not indicate any group differences between anxious and non-anxious parents on any of the parenting behaviors.

Further evidence of the important role of parenting in the etiology of anxiety disorders is derived from studies on children with anxiety disorder (Rapee 1997; Moore et al. 2004; Whaley et al. 1999). However, they assessed the relationship between parenting behaviors and child anxiety, without taking into account the anxiety status of the parents. Most of these studies used questionnaire-based measures (parent and/or child report) to assess parenting behaviors. It was found that childhood anxiety is associated with a parenting style characterized by high parental control and low parental warmth (see Gerlsma et al. 1990; McLeod et al. 2007; Rapee 1997; for reviews). Observational studies also indicated that parents of anxious children exhibit significantly more control and less positive affect during their interactions with their children (Barrett et al. 1996; Dumas et al. 1995; Greco and Morris 2002; Hudson and Rapee 2001; Krohne and Hock 1991; Siqueland et al. 1996). These findings are in accordance with the above mentioned conceptual model for the development of panic attacks and anxiety that suggests that early experiences with parental overprotection and overcontrol might provide information to the child that the world is a threatening place and prevent them from developing adequate sense of control and mastery over their environments.

Taken together, there is theoretical and first empirical support that parental panic disorder may have an impact on parent-child interactions. However, firstly, previous top-down studies did not distinguish between different types of anxiety for parents and children. Secondly, the findings regarding the role of parental control versus parental warmth of anxious parents in interaction with their children is heterogeneous. Thirdly, parenting behavior of anxious parents (and children) may be dependent on whether the interaction situation is anxiety provoking or not.

Thus our first aim was to assess the effect of maternal panic disorder on mother-child interaction, during an actual observed play situation looking at two essential parenting constructs: control vs. granting of autonomy and rejection/criticism vs. warmth. It was hypothesized that panic disordered mothers would be more controlling and exert more criticism toward their children than normal control mothers. Secondly, we tested whether the nature of the task (anxiety producing vs. non-anxiety producing) would accentuate differences in parenting behaviors between anxious and non-anxious mothers and their children. Thirdly, are there differences 
in mother-child interaction between children with and without an anxiety disorder? We hypothesized that mothers would be more controlling and more critical with anxiety disordered children than with normal children. Finally, we investigated associations between parental control, child perceived self-efficacy, child anxiety and maternal panic disorder. We hypothesized that children's perceptions of self-efficacy would be negatively related to parental controlling behaviours and maternal panic disorder but positively to their own anxiety status (Chorpita and Barlow 1998).

\section{Method}

\section{Participants}

The sample consisted of mothers and children at wave two (between April 1998 and April 2001) of a prospective longitudinal high-risk study on panic disorder. Parents with panic disorder (with or without agoraphobia) and their children $(M=11.63$ years, $S D=2.93$ years $)$ had been recruited from outpatient clinics and the parents without a history of psychiatric disorders and their children $(M=11.50$ years, $S D=2.32)$ by newspaper advertisement. The sample of control families were chosen in an attempt to match at best the age and sociodemographic characteristics of the clinical families. At wave two, the children's ages ranged from 13 to 23 years (see table 2). The main reason for our wide age range is that we first approached the parents of the children and only if they agreed to participate, we could gather information about their children's age. As mostly mothers agreed to participate in this study, it was decided to restrict the study to just mothers and their children. The sample consisted of 57 mothers with panic disorder with or without agoraphobia who had 73 participating children and 29 mothers without any current mental disorder who had 34 participating children. Sociodemographic and clinical characteristics of the mothers are shown in Table 1 and of the children in Table 2. All parents and children were diagnosed (during the second assessment point) using a structured interview (Mini-DIPS for the parents: Margraf 1994; F-DIPS for the children: Margraf et al. 1996, German version of the ADIS for DSM-IV, DiNardo et al. 1994) for assessment of mental disorders according to DSM-IV (American Psychiatric Association 1994).

Insert table 1 and 2 about here

Mothers with panic disorder did not differ significantly from mothers without mental disorders in age, type of profession or stable relationship. However, more mothers of the control group had a higher educational 
qualification. There was high comorbidity for the mothers $(52 \%)$ with other mental disorders, in particular with other anxiety disorders and depression. The children did not differ with respect to any sociodemographic feature and on most clinical variables. But children of mothers with panic disorder more often showed life-time anxiety disorders ( $41 \%$ vs. $18 \%)$.

\section{Materials}

Assessment of Mother-Child-Interaction with the Etch a Sketch (AMCIES). Mother-child interaction was observed during a standardized play situation with an Etch-a-Sketch, a toy that allows pictures to be drawn by means of two knobs; one allows horizontal and the other vertical lines to be drawn. Each mother and child dyad were given an Etch-A-Sketch board and instructed to copy a house and a hospital according to a template presented. The presentation of the order of templates provided to the dyads was balanced across sessions. The mother was asked to use only one of the knobs and the child the other one. The two sessions were videotaped. If after 12 minutes there was no completed picture, the individual session was stopped.

Coding. The mother-child interaction was analyzed with a standardized coding system, the "Assessment of Mother-Child-Interaction with the Etch-a-Sketch (AMCIES)" developed by Wolke et al. (1995; Wolke and Meyer 2000; Wolke et al. 2001). Mother, child and interaction scales were used for this purpose ${ }^{1}$.

1) Mother scales: amount/frequency of verbal control $(1=$ high $-9=$ low $)$ assessed over- to undercontrolling behaviour; amount/frequency of criticism $(1=$ very often $-5=$ none $)$ and sensitivity $(1=$ absent $-5=$ high $)$ assessing the reading of the child's cues and appropriately responding to them.

2) Child scales: amount/frequency of verbal control (1= high - 9 low $)$; amount/frequency of criticism $(1=$ very often $-5=$ none $)^{2}$

3) Mother and child interaction scales: Harmony - the amount of conflict within the mother/child interaction $(1=$ many conflicts $-9=$ great harmony); Control over the interaction outcome $(1=$ child is controlling the outcome $-9=$ mother is controlling the outcome) assessed who ultimately determined the outcome of the session. For example, it is not necessarily the one who talks and directs most but the person who leads towards the outcome whether success or failure.

Two psychology students received a training in the use of the AMCIES rating scales by the authors of the AMCIES. Interrater reliability was checked for 30 interactions across the two raters and revealed Kappa

\footnotetext{
${ }^{1}$ The scales of each variable are mentioned in brackets.

${ }^{2}$ The original version of the AMCIES does not contain the scale "child verbal control" This scale was newly developed analog to the "mother verbal control" scale.
} 
coefficients between .76 and .89 .

General self-efficacy (WIRKALL; Jerusalem and Schwarzer 1986). The WIRKALL is a 10-item selfreport questionnaire designed to measure the extent to which individuals believe that situations can be controlled or coped with by their personal efficacy. The items are scored on a 4-point Likert scale, ranging from "not at all true" to "exactly true". Reliability and validity of the scale has been tested in samples from 23 countries with internal consistency ranging from Cronbach's alpha .76 to .90 (Schwarzer 1994). Internal consistency in this sample was Alpha .88 .

\section{Procedure}

The assessments took place at the university laboratory $(33 \%)$ or in the families' homes $(67 \%)$. Mother and child were asked to draw a house and a hospital according to a template presented to them. A house is the standard instruction of the AMCIES and a drawing of a hospital was included as a specific anxiety-provoking stimulus for patients with panic disorder. The sequence in which the house or hospital was to be drawn was balanced. Since a 2 × 2 analysis of variance did not reveal any significant influence of the content of the drawing (house vs. hospital), mean scores for both drawings were combined together in order to obtain one score per participant.

\section{Statistical Analysis}

To test whether mother child-interaction was different between mothers with and without panic disorder, three multivariate analyses of variance with the factor "group" (panic, control) were performed on the (1) three mother scales, (2) two child scales and (3) the two mother and child interaction scales. To control for depression (since $34 \%$ of mothers with panic disorder had an additional diagnosis of depression) we conducted a multivariate analyses of covariance with the factor "group" (panic, control) and the covariate "depression". To assess whether mother-child interaction was different between children with and without anxiety, three likewise multivariate analyses were run. The dependent variables were unchanged, but the factor was replaced by "group" (child with vs. without anxiety disorder). Further multivariate analyses were performed to evaluate the difference in mother-child interaction based on the panic status of the mother as well as the anxiety status of the child.

Given that subject observations were not independent, in that more than one child from some families was tested, an additional analysis controlled for this factor: only one child per family was randomly selected, and all analyses were repeated with the smaller sample. No differences in results between the two samples were observed. Thus results for the total sample will be reported here. 
Results

Mother-child interaction of mothers with and without panic disorder

The results of the mother-child interaction are shown in table 3. Means (standard deviations) and details of the statistical analyses for each scale of the AMCIES are presented separately for each group.

Insert table 3 about here

The overall multivariate analysis of variance performed on all three mother scales revealed a significant group effect $\left(\mathrm{F}_{(3,104)}=6.88, \mathrm{p}<.001\right)$, indicating that mother-child interactions differed between mothers with and without panic disorder. Univariate analyses of each mother scale showed that mothers with panic disorder exhibited significantly more often verbal control, were more critical and significantly less sensitive during the mother-child interaction than mothers without panic disorder (table 3). Multivariate analyses of covariance adjusting for "depression" diagnosis still showed a significant group effect (panic vs. no panic disorder; $\mathrm{F}_{(3,103)}=$ $6.89, \mathrm{p}<.001)$ for the mother scales.

Further multivariate analyses of variance conducted on the mother-child interaction scales and the child scales revealed a significant group effect only for the mother-child interaction scales $\left(\mathrm{F}_{(2,105)}=6.7, \mathrm{p}<.01\right)$, but not for the child scales. Subsequent univariate analyses showed that there was less harmony and more conflict in the panic group and that the mothers more strongly controlled the outcome of the interactions than in the control group. Controlling for comorbid depression in multivariate analysis of covariance did not alter the results (group: $\mathrm{F}_{(2,103)}=7.1, \mathrm{p}<.001$; covariate: $\mathrm{F}_{(2,103)}=.64$, n.s.).

To investigate whether anxious and control families were as likely to be observed in each setting (in the university laboratory vs. at home) a chi-square test was run. A significant difference was found between families with and without a panic disordered mother in terms of the place where mother-child interaction was assessed, $X^{2}{ }_{(1)}=5.41, p<.05$. While control families were as likely to be observed in the laboratory (48.6\%) as at home (51.4\%), anxious families were more likely to be observed at home (74\%) than in the laboratory setting (26\%). Analyses of variance for each individual scale indicated no interactions of maternal status (panic disorder or not) with place of the assessment. However, a significant effect for the factor "place of assessment" for two of the mother scales was found, indicating that mothers were more verbally controlling $\left(\mathrm{F}_{(1)}=14.56, \mathrm{p}<.001\right)$ and less sensitive $\left(\mathrm{F}_{(1)}=4.14, \mathrm{p}<.05\right)$ during interactions in the home setting compared to assessments in the university laboratory. Further analyses of variance neither revealed interactions of maternal panic status with sex or age of the child. Nevertheless, there was a significant sex effect on the child scale amount/frequency of verbal control. 
Sons were more controlling than daughters $\left(\mathrm{F}_{(1)}=4.15, \mathrm{p}<.05\right)$. Finally age was positively correlated with mothers' verbal control $(\mathrm{r}=.25, \mathrm{p}<.01)$, indicating that mothers were less verbally controlling with older children.

\section{Mother-child interaction of children with and without anxiety disorder}

To examine whether mother-child interaction was influenced by the diagnostic status of the children, additional analyses were performed comparing two groups: children with a diagnosis of anxiety disorder $(\mathrm{N}=$ 34) and children without an anxiety diagnosis $(\mathrm{N}=73)$. Multivariate analyses of variance with the factor "group" (child with vs. without anxiety disorder) on the (1) four mother scales, (2) three child scales and (3) two mother and child interaction scales revealed no significant group differences for any of the scales. In an attempt to evaluate the difference in mother-child interaction based on the panic status of the mother as well as the anxiety status of the child, the sample was divided into 4 subgroups: panic mothers with their anxious children $(\mathrm{N}=27)$, panic mothers with non-anxious children $(\mathrm{N}=46)$, non-panic mothers with anxious children $(\mathrm{N}=5)$, and non-panic mothers with non-anxious children $(\mathrm{N}=29)$ (table 4). Since the group of non-panic mothers with anxious children was too small for meaningful statistical comparison, it was excluded. The remaining three groups were compared on each scale of the AMCIES according to multivariate analyses of variance. The analyses revealed significant group differences for the mother scales $\left(\mathrm{F}_{(6,196)}=3.04, \mathrm{p}<.01\right)$, and the motherchild interaction scales $\left(\mathrm{F}_{(4,198)}=3.14, \mathrm{p}<.05\right)$, but not for the child scales $\left(\mathrm{F}_{(4,198)}=1.03\right.$, n.s. $)$. Table 4 displays the results of the univariate tests for each scale of the AMCIES.

Insert table 4 about here

Post-hoc contrasts (Tukey) revealed significant differences between individual groups for the rating scales maternal control and interaction harmony/conflict. Panic mothers with anxious as well as non-anxious children showed significantly more verbal control $(\mathrm{M}=5.23, \mathrm{SD}=1.14 ; \mathrm{M}=5.48, \mathrm{SD}=1.03)$ than non-panic mothers with non-anxious children $(\mathrm{M}=6.16, \mathrm{SD}=1.03), \mathrm{F}_{(2,99)}=6.58, \mathrm{p}<.01$. Furthermore, there were more conflicts during mother-child interaction in the groups of children having a panic disordered mother $(\mathrm{M}=6.21, \mathrm{SD}=$ $1.44 ; \mathrm{M}=6.24, \mathrm{SD}=1.57)$ than in the group with non-panic mothers and non-anxious children $(\mathrm{M}=7.10, \mathrm{SD}=$ $1.34), \mathrm{F}_{(2,99)}=3.88, \mathrm{p}<.05$.

Correlations between self-efficacy, parental control, child anxiety and maternal panic

To determine whether adolescent's perceived self-efficacy was related to parental control, child anxiety, and maternal panic disorder, Spearman's rho correlation coefficients were computed. Perceived self-efficacy was 
lower the higher the parental control $(r=-.21, p<.05)$ and the more anxious the child $(r=-.34, p<.01)$. However, no relation was found between perceived self-efficacy and maternal panic disorder.

\section{Discussion}

This study investigated the effect of maternal panic disorder and child anxiety on mother-child interactions. Our results confirm that mothers with panic disorder with or without agoraphobia were significantly more verbally controlling, less sensitive and more openly critical during the mother-child interaction than mothers without panic disorder. Furthermore, there were more conflicts during the interaction in the panic group than in the control group and the interaction outcome was more often controlled by mothers compared to the control group. These findings are consistent with the results of other top-down studies that found differences in parenting behaviors and expressed emotion between anxious and non-anxious parents (Hirshfeld et al. 1997; Lindhout et al. 2006; Whaley et al. 1999) and concordant with the results of a recent meta-analysis (McLeod et al. 2007) emphasizing the importance of parental control in the development and maintenance of anxiety disorders. No differences in interaction style were found whether a potentially threatening (hospital template) or non-threatening (house template) stimuli was used. This study adds that the interactions of mothers with panic disorder are more dysfunctional than those without panic disorder independent of whether confronted with a child with or without anxiety disorder. In addition, low perceived self-efficacy in adolescents was related to increased parental control and increased levels of anxiety in adolescents, confirming contemporary theories on the etiology of panic and anxiety disorders, positing that parents who exert more control have children with lower levels of perceived self-efficacy and in turn higher levels of anxiety (Bouton et al. 2001; Mineka and Zinbarg 2006; Barlow 2001). Further research is needed to understand the precise role of children's perceived self-efficacy in the transmission of anxiety from parent to child, since this area of research is still in its infancy.

The comparison between children with and without a current diagnosis of anxiety disorder did not show any significant differences with regard to parental behaviors. These findings are in contrast to bottom-up studies, which found a consistent relationship between controlling parental behavior and anxiety-disordered children; and a less consistent relationship between low parental warmth and anxiety-disordered children (see DiBartolo and Helt 2007; McLeod et al. 2007; Rapee 1997). To explore the effect of type of dyad, the sample was divided into four groups, based on the panic status of the mother and the anxiety status of the child. Panic disordered mothers were more verbally controlling towards their children and had more conflicts with their children during the interaction task, regardless of the anxiety diagnosis of their children. These results indicate that maternal anxiety and not child anxiety is the major driver of parenting behaviors. This finding is supported by other 
studies (Dumas et al. 2005; Lindhout et al. 2006; Whaley et al. 1999) examining the parenting behaviors of mothers with anxiety disorder. It stresses the importance of taking into account mother's anxiety diagnosis in future research of child anxiety disorders. Furthermore, after adjustment for the comorbid depression of the mother, we still found that mothers with panic disorder differed significantly in the way they interacted with their children. It underlines the importance of the specific effect maternal panic disorder has on mother-child interaction. Overall, the findings support that mother-child interaction can be affected by maternal panic status. Having over-controlling or overprotective parents may hinder a child from developing appropriate coping strategies in new and strange situations, leading to a poor sense of control and finally to the development of avoidant and anxious behavior (Ballash et al. 2006; Bouton et al. 2001). Thus children of mothers with an anxiety diagnosis are at increased risk for developing anxiety disorders themselves, both because of genetic transmission and as shown here, more controlling, critical and less sensitive maternal interaction style. Therefore, the way mothers behave with their children can be viewed as a mechanism by which they transmit their vulnerability for anxiety to their children. Although the anxiety status of the mother is related to her parenting behaviors, the child's behavior may play a role in eliciting and maintaining these behaviors.

Unraveling the parenting behaviors that affect children's well being and at the same time exploring children's influence on these behaviors will improve treatment by providing families with clear information regarding effective and ineffective interaction behaviors.

There are some limitations of our study. Firstly, the Etch-A-Sketch task included two 12-minute interaction episodes and we do not know how representative our observations are with respect to the usual mother-child interaction. However, the Etch-A-Sketch task is a potentially stressful interaction situation like those found when the parent helps the child with homework or other problem solving focused tasks. Furthermore, the significant differences found between the assessments at home and at university indicated that the mothers' invasive behavior may be even stronger at home than in the laboratory. Secondly, the age range of the children was fairly wide (13-23 years). In view of the meta-analysis of Mcleod et al. (2007), child age does not seem to alter the way parenting behaviors are associated with childhood anxiety. Most reviewed empirical studies demonstrated a stronger association between parental control and childhood anxiety than between parental rejection and childhood anxiety. Therefore, we do not expect a tremendous difference between children's perceptions of family relationships between younger and older samples. Thirdly, the group of non-panic mothers with anxious children (5 dyads) was too small to include in secondary analysis for statistical power reasons. We can thus not conclude with certainty that child anxiety itself may not alter maternal interaction style. Finally, the cross-sectional design of our study does not allow to draw conclusions regarding the causal 
role of parenting in the etiology of panic disorder. This requires a prospective longitudinal study that is currently under way. Future studies have to prove that treatment of maternal anxiety could have a positive effect on mother-child interaction and on the development of panic and other anxiety disorders in their children. 


\section{Acknowledgements}

This research was supported by the German Ministry of Science, Research and Education DLR grant 01 EG 9731/4 and is part of the National Centre of Competence in Research (NCCR) Swiss Etiological Study of Adjustment and Mental Health (sesam) funded by the Swiss National Science Foundation (SNF) (project no. 51A240-104890). The study received ethical permission from the German Association of Psychology. 


\section{References}

Arrindell WA, Emmelkamp PMG, Monsma A, Brilman E (1983) The role of perceived parental rearing practices in the aetiology of phobic disorders: a controlled study. Brit J Psychiat 143:183-187

Arrindell WA, Kwee MGT, Methorst GJ, van der Ende J, Pol E, Moritz BJM (1989) Perceived parental rearing styles of agoraphobic and socially phobic in-patients. Brit J Psychiat 155:526-535

Ballash N, Leyfer O, Buckley AF, Woodruff-Borden J (2006) Parental control in the etiology of anxiety. Clin Child Fam Psychol Rev 9:113-133

Barlow DH (2001) Anxiety and its Disorders, Second Edition: The Nature and Treatment of Anxiety and Panic. The Guilford Press, New York

Barrett PM, Rapee RM, Dadds MM, Ryan SM (1996) Family enhancement of cognitive style in anxious and aggressive children. J Abnorm Child Psychol 24:187-203

Bouton ME, Mineka S, Barlow DH (2001) A modern learning theory perspective on the etiology of panic disorder. Psychol Rev 108:4-32.

Bowlby J (1977) The making and breaking of affectional bonds. I. Aetiology and psychopathology in the light of attachment theory. Br J of Psychiatry 130:120-210

Chorpita BF, Barlow DH (1998) The development of anxiety: The role of control in the early environment. Psychol Bull 124: 3-21.

DiBartolo PM, Helt M (2007) Theoretical models of affectionate versus affectionless control in anxious families: a critical examination based on observations of parent-child interactions. Clin Child Fam Psychol Rev 10:253-274.

Di Nardo PA, Brown TA, Barlow DH (1994) Anxiety disorders interview schedule for DSM-IV lifetime (ADIS-IV-L). Graywind Publications Incorporated, New York

Dumas JE, LaFreniere PJ, Serketick WJ (1995) "Balance of power”: A transactional analysis of control in mother-child dyads involving socially competent, aggressive and anxious children. J Abnorm Psychol 104:104-113.

Faravelli C, Panichi C, Pallanti S, Paterniti S, Grecu LM, Rivelli S (1991) Perception of early parenting in panic and agoraphobia. Acta Psychiatr Scand 84:6-8

Gerlsma C, Emmelkamp PM, Arrindell WA (1990) Anxiety, depression, and perception of early parenting: a meta-analysis. Clin Psychol Rev 10:251-277

Ginsburg GS, Grover RL, Lalongo N (2004) Parenting behaviors among anxious and non-anxious mothers: Relation with concurrent and long-term child outcomes. Child Fam Behav Ther, 26: 23-41 
Goldstein A, Chambless D (1978) A reanalysis of agoraphobia. Behav Ther 9:47-59

Greco LA, Morris TL (2002) Paternal child-rearing style and child social anxiety: Investigation of child perceptions and actual father behavior. J Psychopathol Behav Assess 24:259-267

Hirshfeld DR, Biederman J, Brody L, Faraone SV, Rosenbaum JF (1997) Expressed emotion toward children with behavioral inhibition: Associations with maternal anxiety disorder. J Am Acad Child Adolesc Psychiatry 36:910-917

Hudson JL, Rapee RM (2001) Parent-child interactions and anxiety disorders: an observational study. Behav Res and Ther 39:1411-1427

Jerusalem M, Schwarzer R (1986) Selbstwirksamkeit (Self-efficacy). In: Schwarzer R(ed) Skalen zur Befindlichkeit und Personlichkeit (Mental State and Personality Scales). Department of Psychology, Free University of Berlin, pp 15-28

Krohne HW, Hock M (1991) Relationships between restrictive mother-child interactions and anxiety of the child. Anxiety Stress Coping 4:109-124

Lindhout I, Markus M, Hoogendijk T, Borst S, Maingay R, Spinhoven P, van Dyck R, Boer F (2006) Childrearing style of anxiety-disordered parents. Child Psychiatry Hum Dev 37:89-102

Margraf J (1994) Diagnostisches Kurz-Interview bei psychischen Störungen (Short Diagnostic Structured Interview for Mental Disorders) (Mini-DIPS). Springer, Berlin

Margraf J, Schneider S, Soeder U, Neumer S, Becker ES (1996) Diagnostisches Interview bei psychischen Störungen (F-DIPS). Unpublished manuscript, Technische Universität Dresden.

McLeod BD, Wood JJ, Weisz JR (2007) Examining the association between parenting and childhood anxiety: A meta-analysis. Clin Psychol Rev 27:155-172

Mineka S, Zinbarg R (2006) A contemporary learning theory perspective on the etiology of anxiety disorders. It's not what you thought it was. Am Psychol 61:10-26

Moore PS, Whaley SE, \& Sigman M (2004) Interactions between mothers and children: impacts of maternal and child anxiety. J Abnorm Psychol 113:471-476

Parker G (1979) Reported parental characteristics of agoraphobics and social phobics. Brit J Psychiatry $135: 555-560$

Parker G, Tulping H, Brown LB (1979) A parental bonding instrument. Brit J Med Psychol 52:1-10.

Parker G (1983) Parental overprotection: A risk factor in psychosocial development. Grune \& Stratton, New York.

Rapee RM (1997) Potential role of childrearing in the development of anxiety and depression. Clin 
Psychol Rev 17:47-67.

Schwarzer R (1994) Optimism, vulnerability, and self-beliefs as health-related cognitions: A systematic overview. Psychol Health 9:161-180

Silove D, Parker G, Hadzi-Pavlovic D, Manicavasgar V, Blaszczynski A. (1991) Parental representations of patients with panic disorder and generalised anxiety disorder. Brit J Psychiatry 159:835-841

Siqueland L, Kendall PC, Steinberg L (1996) Anxiety in children: Perceived family environments and observed family interaction. J Clin Child Psychol 25:225-237

Turner SM, Beidel DC, Roberson-Nay R, Tervo K (2003) Parenting behaviors in parents with anxiety disorders. Behav Res and Ther 4:541-554

Weissman MM (1993) Family genetic studies of panic disorder. J Psychiatr Res 27:69-78

Whaley SE, Pinto A, Sigman M (1999) Characterizing interactions between anxious mothers and their children. J Consult Clin Psychol 67:826-836

Wilborg IM, Dahl AA (1997) The recollection of parental rearing styles in patients with panic disorder. Acta Psychiatr Scand 96:58-63

Wolke D, Meyer R (2000) Ergebnisse des Bayerischen Entwickelungsstudie an neonatalen Risikokindern. Implikationen für Theorie und Praxis (Results of the Bavarian development study on neonatal at risk children. Implication for theory and praxis). In: Peterman F, Scheithauer H (Hrsg.) Risiken in der frühkindlichen Entwicklung (Risks during Infantile Development). Hogrefe, Göttingen, pp 114-138

Wolke D, Rios P, Unzer A (1995) AMCIES-Erfassung der Mutter-Kind-Interaktion mit der Zaubertafel AMCIES evaluation of mother-child interaction with the Etch-A-Sketch). Unpublished manuscript, University of Hertfordshire

Wolke D, Schulz J, Meyer R (2001) Entwickelunslangzeitfolgen bei ehemaligen, sehr unreifen Frühgeborenen (Longitudinal developmental implications in past, very immature premature infants). Monatsschr Kinderheilkd (Suppl. 1) 149:53-61

Woodruff-Borden J, Morrow C, Bourland S, Cambron S (2002) The behavior of anxious parents: Examining mechanisms of transmission of anxiety from parent to child. J Clin Child Adolesc Psychol 31:364- 


\section{Table 1}

Sociodemographic and clinical characteristics of mothers. Means (standard deviations) or absolute (relative) frequencies and values of statistical analyses.

\begin{tabular}{|c|c|c|c|}
\hline & $\begin{array}{l}\text { Panic Group } \\
\qquad(\mathrm{N}=57)\end{array}$ & $\begin{array}{l}\text { Control Group } \\
\qquad(\mathrm{N}=29)\end{array}$ & $\begin{array}{c}\chi^{2} \\
(\mathrm{df}=1)\end{array}$ \\
\hline $\operatorname{Age}^{a}$ & $43.37(5.33)$ & $44.25(4.94)$ & $.50^{\mathrm{a}}$ \\
\hline No. of mothers with more than one child & $13(26 \%)$ & $6(21 \%)$ & n.s. \\
\hline Years of education $\leq 10$ years & $39(69 \%)$ & $12(44 \%)$ & \\
\hline Years of education $>10$ years & $17(31 \%)$ & $15(56 \%)$ & $4.64 *$ \\
\hline Employee/house wife & $54(95 \%)$ & $26(93 \%)$ & \\
\hline Management/self employed & $3(5 \%)$ & $2(7 \%)$ & n.s. \\
\hline Stable Partnership & $42(75 \%)$ & $25(86 \%)$ & 1.13 \\
\hline \multicolumn{4}{|l|}{ Primary diagnosis: } \\
\hline Panic Disorder without Agoraphobia & $1(2 \%)$ & 0 & \\
\hline Panic Disorder with Agoraphobia & $56(98 \%)$ & 0 & \\
\hline \multicolumn{4}{|l|}{ Additional/past diagnoses } \\
\hline Social Phobia & $3(6 \%)$ & 0 & \\
\hline Specific Phobia & $11(22 \%)$ & $2(7 \%)$ & \\
\hline Generalised Anxiety Disorder & $5(10 \%)$ & 0 & \\
\hline Major Depression & $17(34 \%)$ & $1(4 \%)$ & n.s. \\
\hline Dysthymia & $4(8 \%)$ & 0 & \\
\hline Hypochondria & $1(2 \%)$ & 0 & $* * \mathrm{~b}$ \\
\hline Somatization Disorder & $3(6 \%)$ & 0 & \\
\hline Bulimia & $1(2 \%)$ & 0 & \\
\hline Substance Abuse & $3(6 \%)$ & 0 & \\
\hline Comorbidity & $26(52 \%)$ & 0 & \\
\hline
\end{tabular}

Notes: $\chi^{2}=$ Computed value of a chi-square test

${ }^{\mathrm{a}}$ Mean and Standard deviation; $t=$ computed value of $t$ test

${ }^{\mathrm{b}}$ Fisher's exact test; ${ }^{*} p<0.05,{ }^{* *} p>0.01, * * * p<0.001$. 


\section{Table 2:}

Sociodemographic and clinical characteristics of children. Means (standard deviations) or absolute (relative) frequencies and values of statistical analyses.

\begin{tabular}{|c|c|c|c|}
\hline & $\begin{array}{l}\text { Panic Group } \\
\qquad(\mathrm{N}=73)\end{array}$ & $\begin{array}{l}\text { Control Group } \\
\qquad(\mathrm{N}=34)\end{array}$ & $\begin{array}{c}\chi^{2} \\
(d f=1)\end{array}$ \\
\hline $\mathrm{Age}^{\mathrm{a}}$ & $17.22(2.96)$ & $18.18(2.04)$ & $1.95^{\mathrm{a}}$ \\
\hline Female & $40(55 \%)$ & $18(53 \%)$ & .03 \\
\hline Living with at least one parent & $63(86 \%)$ & $32(94 \%)$ & n.s. \\
\hline \multicolumn{4}{|l|}{ Lifetime Diagnoses: } \\
\hline Panic Disorder without Agoraphobia & $2(3 \%)$ & 0 & \\
\hline Panic Disorder with Agoraphobia & $3(4 \%)$ & 0 & \\
\hline Agoraphobia without Panic Disorder & $1(1 \%)$ & 0 & \\
\hline Social Phobia & $14(19 \%)$ & $2(6 \%)$ & 3.23 \\
\hline Specific Phobia & $24(33 \%)$ & $6(18 \%)$ & 1.20 \\
\hline Generalised Anxiety Disorder & $1(1 \%)$ & 0 & \\
\hline Obssessive-Compulsive Disorder & $2(3 \%)$ & 0 & \\
\hline Separation Anxiety Disorder & $5(7 \%)$ & 0 & \\
\hline Major Depression & $3(4 \%)$ & $4(12 \%)$ & .21 \\
\hline Somatization Disorder & $2(3 \%)$ & 0 & \\
\hline Attention-Deficit/Hyperactivity Disorder & 0 & $1(3 \%)$ & \\
\hline Oppositional Defiant Disorder & $1(1 \%)$ & $1(3 \%)$ & \\
\hline Conduct Disorder & $1(1 \%)$ & 0 & \\
\hline Axiety Disorders (lifetime) & $30(41 \%)$ & $6(18 \%)$ & $5.71 *$ \\
\hline Anxiety Disorder (current) & $23(32 \%)$ & $5(15 \%)$ & n.s. \\
\hline Comorbidity & $18(25 \%)$ & $3(9 \%)$ & $.06^{\mathrm{b}}$ \\
\hline
\end{tabular}

Notes: $\chi^{2}=$ Computed value of a chi-square test

${ }^{\mathrm{a}}$ Mean and Standard deviation; $t=$ computed value of $t$ test

${ }^{\mathrm{b}}$ Fisher's exact test; ${ }^{*} p<0.05,{ }^{* *} p>0.01,{ }^{* * *} p<0.001$. 


\section{Table 3:}

Mother-child interaction with the Etch-a-Sketch between mothers with and without panic disorder; Means (standard deviations) per group and scale, as well as values of univariate tests and effect sizes.

\begin{tabular}{|c|c|c|c|c|}
\hline Scale & $\begin{array}{l}\text { Panic group } \\
\qquad(\mathrm{N}=73)\end{array}$ & $\begin{array}{l}\text { Control group } \\
\qquad(\mathrm{N}=35)\end{array}$ & $\boldsymbol{F}$ & $\eta^{2} \mathbf{p}$ \\
\hline & $M(S D)$ & $M(S D)$ & & \\
\hline Mother scales $(d f)$ & & & $(3,104)$ & \\
\hline Verbal control (Scale 1-9) & $5.32(1.11)$ & $6.16(1.04)$ & $13.99 * * *$ & .12 \\
\hline Critic (Scale 1-5) & $4.73(0.61)$ & $4.94(0.20)$ & $3.89 *$ & .04 \\
\hline Sensitivity (Scale 1-5) & $3.42(1.07)$ & $3.89(0.99)$ & $4.6^{*}$ & .04 \\
\hline Child scales $(d f)$ & & & $(2,105)$ & \\
\hline Verbal control (Scale 1-9) & $4.72(1.51)$ & $4.54(1.18)$ & .367 & .00 \\
\hline Critic (Scale 1-5) & $4.58(.67)$ & $4.77(.44)$ & 2.472 & .02 \\
\hline$\underline{\text { Interaction scales }}(d f)$ & & & $(2,105)$ & \\
\hline Harmony (Scale 1-9) & $6.22(1.48)$ & $7.00(1.30)$ & $7.128 * *$ & .06 \\
\hline Control (Scale 1-9) & $5.01(1.88)$ & $4.26(1.58)$ & $4.165^{*}$ & .04 \\
\hline
\end{tabular}

Note: $\eta^{2} \mathrm{p}=$ partial eta-squared (effect size value)

$* p<0.05, * * p>0.01, * * * p<0.001$. 


\section{Table 4:}

Mother-child interaction with the Etch-a-Sketch between different dyadic subgroups; Means (standard deviations) per subgroup and scale, as well values of univariate tests and corresponding effect sizes.

\begin{tabular}{|c|c|c|c|c|c|}
\hline Scale & $\begin{array}{l}\text { PD mothers with } \\
\text { AD children } \\
(\mathrm{N}=27)\end{array}$ & $\begin{array}{l}\text { PD mothers with } \\
\text { non-AD children } \\
\qquad(\mathrm{N}=46)\end{array}$ & $\begin{array}{l}\text { Non-PD mothers with } \\
\text { non-AD children } \\
(\mathrm{N}=29)\end{array}$ & $\boldsymbol{F}$ & $\eta^{2} \mathbf{p}$ \\
\hline & $M(S D)$ & $M(S D)$ & $M(S D)$ & & \\
\hline$\underline{\text { Mother scales }}(d f)$ & & & & $(3,96)$ & \\
\hline Verbal control (Scale 1-9) & $5.48(1.03)$ & $5.23(1.14)$ & $6.16(1.03)$ & $6.58 * *$ & .12 \\
\hline Critic (Scale 1-5) & $4.74(.45)$ & $4.73(.70)$ & $4.93(.22)$ & 1.43 & .03 \\
\hline Sensitivity (Scale 1-5) & $3.33(1.03)$ & $3.48(1.06)$ & $3.91(.97)$ & 2.42 & .05 \\
\hline$\underline{\text { Child scales }}(d f)$ & & & & $(2,97)$ & \\
\hline Verbal control (Scale 1-9) & $4.94(1.71)$ & $4.59(1.39)$ & $4.53(1.28)$ & .69 & .01 \\
\hline Critic (Scale 1-5) & $4.52(.60)$ & $4.61(.71)$ & $4.79(.43)$ & 1.48 & .03 \\
\hline$\underline{\text { Interaction scales }}(d f)$ & & & & $(2,98)$ & \\
\hline Harmony (Scale 1-9) & $6.24(1.57)$ & $6.21(1.44)$ & $7.10(1.34)$ & $3.88^{*}$ & .07 \\
\hline Control (Scale 1-9) & $5.07(2.24)$ & $4.97(1.65)$ & $4.28(1.70)$ & 1.67 & .03 \\
\hline
\end{tabular}

Note: the subgroup of non-panic mothers with anxious children is not included since it lacks statistical power. $\eta^{2} \mathrm{p}=$ partial eta-squared (effect size value)

$* p<0.05, * * p>0.01, * * * p<0.001$. 